\title{
O HABITAT da "NÃO CIDADE" como um problema para a Arquitetura e Urbanismo
}

\author{
LOPES, João Marcos de Almeida ${ }^{1}$ \\ LENZI, Cecília Corrêa ${ }^{2}$ \\ BORGES, Amadja Henrique ${ }^{3}$
}

\begin{abstract}
1Instituto de Arquitetura e Urbanismo, Universidade de São Paulo, São Carlos-SP, Brasil. jmalopes@sc.usp.br 2 Instituto de Arquitetura e Urbanismo, Universidade de São Paulo, São Carlos-SP, Brasil. ceciliaclenzi@gmail.com 3 Universidade Federal do Rio Grande do Norte, Natal-RN, Brasil. amadjaufrn@gmail.com
\end{abstract}

O Brasil é um país urbano - ponto.

Entretanto, a seara do debate sobre noções e designações quanto ao que efetivamente seja o campo e quanto à tipologia e qualidade das relações que ele estabelece com a cidade vem sendo, por aqui, razoavelmente cultivada, pelo menos desde os anos 1950 e $1960^{1}$.

Cabe lembrarmos que a definição oficial de "cidade" - ainda vigente - é de 1938 quando, a partir do Decreto no 311 , publicado já no

1 Como afirma Valadares, citando seu colega de IPEA, Guilherme Costa Delgado: "não é um acaso histórico que a contraposição entre o rural e o urbano tenha começado a se afirmar como questão nacional justamente nas décadas de 1950 e 1960, quando as proporções relativas das populações rural e urbana se inverteram e esta última passou a ser majoritária. Estavam em voga então a ideia de que o campo território no qual prevaleciam relações sociais arcaicas - constituía obstáculo à modernização do país, e a visão funcionalista segundo a qual o rural devia servir ao desenvolvimento urbano-industrial, fornecendo matérias-primas baratas e alimentos a baixo preço rebaixando o custo de reprodução da força de trabalho -, gerar divisas com a exportação e, posteriormente, liberar mão de obra para os setores secundário e terciário (Delgado, 2005 apud Valadares, 2014, p.28). contexto do Estado Novo, propunha-se uma concepção de "cidade" a favor do binômio industrialização-urbanização. Segundo essa normativa, todo e qualquer núcleo urbano que constituísse uma sede municipal passaria a ser considerado "cidade" - independentemente das especificidades espaciais e demográficas dessas sedes (Valadares, 2014, p.8; parece pertinente considerarmos como especificidades: densidade populacional e construtiva, caracterização das atividades econômicas preponderantes, padrão da infraestrutura urbana, modos de vida, entre outras). É evidente o impacto não só prático mas também ideológico que a promoção desses núcleos urbanos à condição de "cidade" acabou produzindo "sobre a configuração oficial da divisão dos espaços urbanos e rurais do país" (idem): não é necessário nos estendermos quanto à utilidade dessa concepção na afirmação da modernidade vinculada ao urbano e o arcaico ao mundo rural.

Após 1946, com a constituição pós Estado Novo e a ampliação da autonomia dos entes 
federados, a competência para definição dos limites do perímetro urbano passa às câmaras e prefeituras municipais. Novamente, também não é necessário nos estendermos quanto às consequências dessa transferência de atribuição: os critérios para a definição do perímetro urbano passaram a se orientar muito mais em função das necessidades de arrecadação (ampliação das unidades territoriais sujeitas à tributação municipal) - e não em função dos arranjos produtivos e das relações de produção, da composição e densidade demográfica, dos modos de vida e estratégias de sobrevivência etc. ${ }^{2}$. Os censos demográficos e estudos estatísticos ficam, assim, comprometidos, e abrem caminho para as mais diversas interpretações a respeito das necessidades e transformações vividas pelo campo brasileiro.

A título de esboço do horizonte do debate em torno dessas interpretações - que se dá particularmente na Geografia, na Economia e entre Cientistas Sociais (muito pouco disso chega à Arquitetura e Urbanismo) -, utilizaremos interessadamente a disposição defendida por Ariovaldo Umbelino de Oliveira (Oliveira, 2004) que delineia pelo menos três vertentes que, digamos, acabam repercutindo as disputas quanto às concepções e posições sobre a estrutura fundiária vigente no país, sobre as políticas de distribuição da terra e de fomento à produção agropastoril, sobre as formas mais ou menos combativas de organização campesina - ou até mesmo se existe ou não o "campesinato" - etc. Apesar dos antagonismos, mais ou menos estridentes, menores ou maiores presenças à parte, todas

\footnotetext{
2 Basta lembrarmos, no contexto da economia rural, a diversidade dos arranjos produtivos possíveis, protagonizados pelos agentes econômicos que o são os camponeses, proprietários ou não, que não são considerados na hora de se definir os limites do perímetro urbano: desde a produção familiar ou cooperativada, passando pela meação, arrendamento e até o assalariamento etc., são especificidades que, via de regra, são esquecidas em função dos 'benefícios', diretos e indiretos, da transformação de unidades de território rural em zona urbana. Como sugere Valadares, até mesmo o Estatuto da Cidade e os Planos Diretores acabam consolidando a idéia do campo como um banco de terras disponíveis para alimentar o crescimento urbano.
}

essas vertentes concordam que os critérios utilizados pelos municípios para delimitação do perímetro urbano - e, por consequência, da zona rural que "sobra" - são provenientes de decisões primordialmente administrativas, movidas mais por expectativas de arrecadação municipal do que fruto de um planejamento territorial, como vimos. De todo modo, os protagonistas dessas vertentes vêm empenhando esforços na construção de uma percepção mais ajustada do que seja o rural, de uma noção mais precisa do significado de uma reforma agrária no país, do papel dos movimentos sociais na construção dessas definições etc.

Uma primeira vertente reúne autores que, tomando como referência os dados estatísticos de populações tipicamente urbanas casualmente classificadas como rurais só por estarem fora do perímetro urbano, afirmam que as relações de produção vigentes no meio rural estão se transformando e que, em um futuro próximo, o espaço rural não mais existirá - tudo será urbano. Esse grupo acredita que, para que seja possível vislumbrarmos alguma evolução posterior - e superior - essas relações de produção precisam 'amadurecer', por assim dizer, e atravessar uma etapa de relações integralmente conformadas pelo modo capitalista de produção, eliminando as relações não-capitalistas praticadas pelo campesinato. Por isso o campesinato deve desaparecer, dando lugar aos assalariados, num primeiro momento, e a formas de organização produtiva mais avançadas, numa segunda etapa (Ignacio Rangel é um desses autores, por exemplo).

Um segundo grupo de autores também acredita na extinção do campesinato, mas por outras razões: segundo eles, já estaria em curso uma espécie de 'purificação' das relações de produção no campo brasileiro, ou seja, num futuro próximo todos os operários dos complexos agroindustriais deverão ter salários, carteira assinada e direitos trabalhistas (fundamentalmente reúnem-se aqui José Graziano da Silva, Ricardo Abramovay e José Eli da Veiga, dentre outros). Para estes autores a reforma agrária deixa de ser necessária, uma 
vez que já teria passado a conjuntura social, econômica e tecnológica que a colocava como demanda política. Também defendem que as falhas na aferição da população rural são resultantes de metodologias inadequadas - e que devem ser corrigidas. Dessa forma, o método do cálculo estatístico utilizado pelo IBGE deve ser modificado para que tenhamos dados mais representativos e confiáveis quanto à proporção entre o rural e o urbano no Brasil. Para este segundo grupo de autores, o país teria na realidade mais de $30 \%$ de sua população vivendo em áreas consideradas rurais ou "intermediárias", frente aos atuais $15,64 \%$ registrados pelo censo de $2010^{3}$.

3 O estudo proposto por Valadares em "O gigante invisível - território e população rural para além das convenções oficiais", de 2014, procura justamente ponderar a metodologia utilizada para aferição do contingente populacional urbano e rural no país. Segundo este autor, não é objetivo de seu estudo "propor um critério de contagem da população rural que se contraponha ao oficial ou que possa substituí-lo, mas apenas oferecer uma leitura crítica, calcada em elementos quantitativos, do conceito oficial de população rural" (Valadares, 2014, p.35). De todo modo, para levar a cabo essa "leitura crítica" e tomando como referência o Censo 2010 - segundo o qual o país apresentava, naquele momento, uma população urbana equivalente a $84,36 \%$, contra uma população rural equivalente a $15,64 \%$ - Valadares propõe o exercício de três abordagens metodológicas, ensaiando algumas alternativas para uma aferição mais precisa da população rural brasileira: a primeira, utilizando como referência critérios da OCDE (Organização para a Cooperação e o Desenvolvimento Econômico), segundo os quais a população rural em 2010 equivaleria a $38,85 \%$ da população total do país; a segunda, orientada a partir de critérios defendidos por José Eli da Veiga em alguns de seus trabalhos (Veiga, 2002 e 2004), o resultado seria uma população rural correspondendo a $25,47 \%$ do total (isso sem contar uma tipologia "intermediária", entre o urbano e rural, equivalente a $15,84 \%$ no primeiro estudo e a $12,81 \%$ no estudo patrocinado pelos critérios de Eli da Veiga); por fim, Valadares ensaia sua própria tipologia, fazendo uso sumário dos dados do Censo 2010 e adotando "critérios de recontagem" que dessem destaque aos indícios inequívocos do "grau de ruralidade de um município": por exemplo, a "proporção da sua população rural sobre o total, em função da proporção dos seus ocupados na agropecuária e em função da sua densidade demográfica". Utilizando-se desse expediente, conjugando alguns outros critérios e excluindo algumas sobreposições, Valadares chega a uma população rural equivalente a 43,1 milhões de pessoas, $22,6 \%$ do total, "cerca de 14 milhões a mais que o dado oficial" (Valadares, 2014, p.33). De todo modo, ou por uma via
Essas duas vertentes, entretanto, protagonizam uma disputa fundamentalmente estatística e, para efeitos analíticos, não consideram - ou pouco consideram - a realidade e o cotidiano das relações que se dão sobre o território.

Mais recentemente, questionando a serventia desta disputa estatística, alguns autores vêm propondo interpretar a relação campo-cidade como uma unidade contraditória, interdependente, costurada permanentemente por relações de trabalho, troca e produção. Ou seja, mais do que uma discussão que toma como referência dados estatísticos que resultam de metodologias censitárias discutíveis, importa entender e interpretar as especificidades da realidade social que está em questão. Tais autores, portanto, reúnem-se numa terceira vertente que defende que o campesinato, por não submeter seu trabalho ao capital - apenas a sua renda -, estabelece mecanismos diferentes e alimenta uma produção nãocapitalista que é necessária para a constante acumulação primitiva do capital. Isso significaria que o campesinato não pode desaparecer pela simples razão de que o capitalismo, para sua própria saúde, precisa dele ${ }^{4}$.

Entretanto, essa espécie de taxonomia do pensamento sobre o rural brasileiro contribui muito mais para compreendermos as concepções que informam o campo das disputas pelo formato das políticas para o campo brasileiro ${ }^{5}$, do que para aprofundarmos a interpretação das dualidades entre cidade e campo - ou "a não cidade". Parece-nos pertinente, contudo, considerar que esse debate ao menos contribui para nos apresentar, arquitetos e urbanistas que somos, a questão da caracterização e diferenciação dos espaços urbanos e rurais - o que é fundamental para uma abordagem crítica do problema do habitat

ou por outra, parece que o Brasil é bem menos urbano do que aparece nas estatísticas oficiais.

4 Para maior aproximação do assunto, ver Graziano da Silva (1998), Veiga (2000), Carlos (2000) e Oliveira (2004).

5 É claro que afirmações como "o campesinato está em extinção" interessam a determinados setores do poder, assim como "o capital precisa do campo" interessam a outros. 
do campo, das águas e das florestas e das políticas de promoção e provisão da moradia nesses contextos.

Apesar dos possíveis alinhamentos e antagonismos entre concepções, entre esta ou aquela vertente, parece-nos certo que as três tendências aqui registradas apontam para 0 consenso de que se faz necessária, a partir da Arquitetura e do Urbanismo, uma atenção mais cuidadosa para o problema do campo. Isto porque a imprecisão do seu significado vem implicando, de modo recorrente, a afirmação sorrateira de uma espécie de "cidadania de segunda ordem", isto é, concede-se tacitamente que a cidadania - pela facilidade da associação etimológica e/ou por uma recalcitrante visão dicotômica do mundo - é atributo exclusivo daquele sujeito essencialmente urbano, do morador da cidade. De aí decorre o também recorrente esquecimento de que o morador do campo - do campo, das florestas e das águas , além de agente primeiro na base produtiva que sustenta as ordens econômicas dos setores ditos 'avançados', é também um legítimo demandante de alguma atenção por parte do Estado. Assim como há os esquecidos da cidade, também o campo abriga os seus - com a diferença que estes últimos literalmente desaparecem por entre as inúmeras dobras dos lugares que habitam e que se multiplicam em suas polissêmicas formas de aparição: para além do "rural" em discussão, também estão ali, nas franjas das cidades, em diversos enclaves nas áreas periféricas dos grandes centros urbanos, nas comunidades quilombolas, caiçaras e ribeirinhas, nos territórios ocupados pelos povos da floresta e, por fim, nas inúmeras modalidades de assentamentos chamados "de reforma agrária" - que já vêm mudando a dinâmica de diversos municípios país afora, agregando populações, da noite para o dia, por vezes maior que o contingente populacional originalmente ali instalado. Como vimos, essa desaparição pode ser constatada nas tabelas dos resultados censitários que teimam apagar sua presença, paradoxalmente promovendo sua sistemática inclusão no contingente de população urbana, determinada por sua "situação de domicílio". Ao desaparecer, o morador do campo deixa de ser um problema ou uma questão também para a Arquitetura e o Urbanismo.

Procurando não entrar na justa seara dos geógrafos, economistas e cientistas sociais, parece-nos que há uma especificidade das relações sociais entre campo e cidade no contexto brasileiro que nos remete para além da estrita discussão sobre a relação urbano/rural vigente. Buscando fugir de uma visão dicotômica, acreditamos que há articulações mais complexas entre campo e cidade, alinhavadas pelas inúmeras contradições que Ihes são correlatas, principalmente se nos atentarmos em detalhe para a dinâmica das diversas modalidades desses espaços concebidos ou formas de existência fora das cidades esparramadas pelo território nacional: com tipicidades próprias, intervindo na lógica das relações sociais que transbordam os limites entre o urbano e o rural, estabelecem um tecido contínuo - em termos lefebvrianos - pelo qual transitam e se adensam as formas sociais, econômicas e culturais contraditórias que produzem tanto o campo como a cidade.

Para ilustrar o que queremos dizer, cabe aqui um exemplo: se num primeiro momento aqueles destituídos de tudo, acampados às margens das rodovias, são designados com toda a sorte de adjetivos que faria ofender o mais perverso meliante, ao serem contemplados com lotes e moradias nos projetos de responsabilidade do Estado - INCRA ou, em menor escala, de órgãos estaduais - passam a figurar, no contexto dos municípios nos quais tais assentamentos são instalados, como atraente 'mercado consumidor' - e, mais significativo ainda, como suculenta base eleitoral. Desse modo, estes sujeitos, quando na condição de assentados, quando são conduzidos aos ritos de 'integração à sociedade', não o são como cidadãos, como sujeitos de direitos, porém como consumidores ou eleitores.

Parece-nos certo que, dadas as dinâmicas de como o mercado regula seus interesses e as circunstâncias atuais em que se realiza nossa democracia representativa, a entrada dos novos assentados no círculo civilizatório vigente - 
dominado e ordenado pelo capital - os faz reféns de si mesmos, de sua frágil porém sempre ideológica condição de "pequenos produtores rurais", de "agricultores familiares"... porém nunca "camponeses"6. Tais ambiguidades acabam se estendendo às formas históricas de organização do campesinato brasileiro, reproduzindo as incongruências particulares nas estruturas movimentistas, sindicais e federativas que congregam os trabalhadores rurais, tornando-as reféns, por sua vez, dos programas públicos de fomento à produção, instalação e produção de moradias.

No entanto, não se pode negar que esses assentamentos e formas de viver fora das cidades seguem se territorializando no país, ampliando suas complexas dinâmicas de produção e de habitats concebidos e vividos, reverberando os mesmos dilemas e contradições experimentados pelos pobres urbanos - porém, ali, de forma acentuadamente hipertrofiada: para aqueles "pequenos produtores rurais", por exemplo, não são válidos os valores praticados na cidade para financiamento de moradias através do "Minha Casa Minha Vida". Até 2016, os valores para construção definidos para financiamento de famílias de mais baixa renda através do Programa Nacional de Habitação Rural, vinculado ao "Minha Casa Minha Vida" PNHR/MCMV (Grupo 1, como denominado nas normativas do programa) iam de $R \$ 34.200,00$ a $\mathrm{R} \$ 36.600,00$, dependendo da região do país. No seu equivalente urbano, o MCMV-Entidades, os valores praticados em 2016 podiam chegar a $\mathrm{R} \$ 93.000,00$ - ou aproximadamente $\mathrm{R} \$ 80.000,00$, se excluirmos uma estimativa de parcela para cobertura do custo da terra ${ }^{7}$.

\footnotetext{
6 Não é demais lembrar a evocação "somos todos agricultores!" como bandeira de unificação do campo, proposta pela senadora Kátia Regina de Abreu, exministra da Agricultura, Pecuária e Abastecimento e então presidente da Confederação da Agricultura e Pecuária do Brasil (CNA).

7 Para uma explanação mais cuidadosa sobre o assunto, ver LENZI, Cecília Corrêa. A habitação camponesa no programa MCMV. 2017. Dissertação (Mestrado em Arquitetura e Urbanismo) - Instituto de Arquitetura e Urbanismo, Universidade de São Paulo, São Carlos, 2017.
}

Grosso modo, essa diferença acaba insinuando que o camponês é aproximadamente $55 \%$ 'menos cidadão' que seu correlato urbano. Concede-lhe assim a incômoda porém estratégica condição de um "cidadão de segunda ordem" - incômoda, porque não é fácil ver-se destituído de, pelo menos, o que seu companheiro da cidade dispõe; estratégica, porque mantê-lo reduzido ao seu lugar na sociedade é sempre uma questão funcional.

É nesse contexto que, desde a realização em setembro de 2006 do I Colóquio "Habitat e Cidadania: habitação de interesse social no campo" em Natal/RN, um grupo de instituições e pesquisadores vêm trabalhando no aprofundamento das reflexões sobre as dimensões e especificidades do morar fora das cidades, procurando formular um quadro crítico que nos permita abordar a questão como um problema pertinente à Arquitetura e do Urbanismo. Assim, tanto na segunda edição do Colóquio "Habitat e Cidadania", realizada em São Carlos/SP, em maio de 2011, como em sua terceira edição, realizada em maio de 2015 em Brasília/DF, entre idas e vindas, afinidades e controvérsias, foi-nos possível acumular algumas reflexões e realizar algumas interlocuções mais sistemáticas que resultaram nesta edição da Paranoá, toda ela dedicada à discussão sobre o habitat no campo, nas águas e nas florestas - isto é, todos aqueles espaços que não se enquadram nos cânones do regime de relações (sociais, de produção, culturais etc.) que efetivamente configuram o urbano, mas que se apresentam, tanto quanto as cidades, como espaços que também demandam aguda atenção - e não só dos arquitetos e urbanistas, mas também dos gestores públicos e das políticas públicas em geral.

Desse modo, Rodolfo Sertori, Cecília Lenzi e Angel Castañeda Rodriguez retomam parte dos debates e das propostas que advieram do I Colóquio em 2006 e que afloraram no II Colóquio em 2011 para, a partir daí, articular e destacar pelo menos duas das principais questões que mobilizaram as discussões na 
terceira edição do evento, em 2015: por um lado, a latente porém patente divergência entre grupos, organizações e movimentos mais 'alinhados' com as instâncias governamentais e aqueles que, orientados por posturas mais ou menos antagônicas, recusam relações de dependência e heteronomia na luta pelas políticas e investimentos públicos; por outro lado, a retomada da reforma agrária como campo de disputas - tanto teóricas como práticas - que nos faz ver a sua indissociabilidade com a questão do habitat fora do meio urbano, como uma ação politicamente necessária e vital para a constituição de condições dignas não só de produção nesses contextos, mas também de vida plenamente vivida. A partir daí os autores questionam os parâmetros que nos orientam os processos de formação profissional vigentes: se aqueles "nãos cidadãos" são invisíveis à Arquitetura e ao Urbanismo, como pensarmos a relação da temática do habitat no campo, nas águas e nas florestas com a formação dos futuros arquitetos? Como eventualmente as atividades de extensão ou de formação complementar (as residências profissionais, por exemplo) e mesmo as parcerias com organizações não governamentais que atuam diretamente na assessoria para produção desses habitats podem contribuir para o aprofundamento de nossa ciência desses contextos? E, por fim, como essas iniciativas poderiam iluminar $e$ promover a formulação de programas e políticas mais concernentes e adequadas a esses contextos?

$\mathrm{Na}$ sequência, as contribuições concorrem justamente para a discussão sobre as inadequações, invisibilidades, acertos e desacertos nas abordagens de trabalho de pesquisa e assessoria etc., buscando dar corpo e concretude às questões inicialmente enunciadas.

Abrindo o Eixo Temático n1 - Políticas públicas habitacionais para o campo, as águas e as florestas, Aline Carvalho, Nayara de Paula e Dafhini Pereira discutem os parâmetros estabelecidos para a produção habitacional no âmbito do Programa Nacional de Habitação Rural - o PNHR - que, ao ser subsumido pelo Programa "Minha Casa Minha Vida", acaba induzindo, ainda que indiretamente, a adoção de tipologias habitacionais que nada têm a ver com a realidade do campo, o modo de vida rural e os hábitos dos moradores (dimensões e áreas, distribuição de cômodos, padrão do mobiliário mínimo etc.).

Questionando como os levantamentos técnicos praticados na arquitetura e no urbanismo são orientados metodologicamente, Silke Kapp apresenta reflexões feitas a partir da aproximação investigativa de um vilarejo rural, o Quartel do Indaiá, no município de Diamantina, Minas Gerais. Se podemos distinguir as recorrentes inadequações entre as soluções arquitetônicas e construtivas ou de planejamento e de políticas públicas e o modo de vida camponês, certamente não resolveríamos 0 problema simplesmente passando a apenas dar atenção a tais particularidades. Mais que isso, faz-se necessário estabelecer novas formas de abordagem frente à realidade que se apresenta - e isto é o que propõe o texto de Kapp: um "método de levantamento sócio-espacial" que enfrente as especificidades do contexto com a devida amplitude e apuro necessário.

Concluindo as contribuições para esse eixo, Taísa Brosler e Sonia Maria Bergamasco também apresentam alternativa metodológica para que se faça possível uma apreensão da realidade vivida pelos assentamentos rurais agora já a posteriori do momento da instalação.

As autoras propõem um "indicador" que, formulado a partir das informações obtidas com o instrumental de pesquisa utilizado, permite verificar padrões que indicariam o quanto 0 exercício do direito de moradia vem se efetivando no contexto pesquisado. Num ambiente em que as mazelas do cotidiano desaparecem na dispersão espacial que caracteriza a moradia no campo, nas águas e nas florestas, como acurar os sentidos para tatearmos os meios que nos asseguram 0 exercício de diretos? 
Já no Eixo Temático no2 - Projeto de habitat para o campo, as águas e florestas, o primeiro texto, de autoria de Marina Caraffa, propõe discutir criticamente $\mathrm{o}$ argumento que defende o Projeto de Assentamento como "instrumento de materialização da política de reforma agrária"- quais seus limites práticos, verificados ao longo do tempo, qual a magnitude dos impactos ambientais gerados, com quais fragilidades hoje as famílias assentadas têm que se haver etc. A partir do contexto discutido, a reflexão da autora nos induz reconhecer o quanto se faz incompleto o debate sobre a reforma agrária no país: as soluções programáticas que vêm sendo implementadas, a precariedade operacional das instâncias responsáveis pela gestão dos projetos de assentamento, a exiguidade de recursos investidos etc. - todas essas são condições que nos colocam de frente à questão quanto à validade do modelo que vem sendo praticado.

A seguir, Liza de Andrade, Vânia Loureiro, Caio Silva e Luiz Felipe Machado nos apresentam uma experiência de planejamento participativo, empreendida com vistas ao parcelamento do solo da Ecoagrovila Renascer, em Planaltina, no DF. A discussão sobre o planejamento do lugar trouxe, conforme os autores, a abertura para discussão quanto às possibilidades de se compatibilizar a produção tradicional com alternativas mais sustentáveis de cultivo e manejo do solo. Cabe atentarmos para o fato de que se trata de uma iniciativa ao mesmo tempo promovida por um Escritório Modelo - o CASAS - Centro de Ação Social em Arquitetura Sustentável, vinculado à UnB - e articulada à grade curricular, através da disciplina PEMAU Prática em Escritório Modelo de Arquitetura e Urbanismo. Essa é uma novidade que reverbera algumas questões já tratadas aqui e que nos sugere possibilidades a nosso alcance quanto à formação de arquitetos e urbanistas que se atentem para os problemas do habitat rural.

Contribuindo com a única comunicação no Eixo Temático no3 - Direito ao Território e Legislação Fundiária (foram poucas submissões para a discussão desta temática),
Paula Moreira, Edite Diniz, Guiomar Germani e Silvio Machado trazem a discussão sobre as comunidades tradicionais e sobre o quanto seus habitats contribuem para a preservação de sua cultura e modos de vida. Partindo ao meio as frágeis ligaduras que sustentam os mecanismos de defesa da comunidade quilombola estudada, a disputa pela real 'propriedade' da terra (aquela, "para quem nela trabalha") e a luta pela permanência no território são determinantes que acabam evidenciando, segundo os autores, a identidade política do grupo, decisivamente forjada pelo conflito.

Por fim, o Eixo Temático n4 - Participação, formação e geração de trabalho e renda nos processos de projeto e produção habitacional traz, primeiramente, o trabalho de Thiago Ferreira e Anaïs Perrin. Trata-se do relato de uma atividade de extensão, promovida no âmbito de um programa de modalidades de formação em processos e técnicas construtivas - o "Canteiro-Escola", mantido pelo HABIS/IAU/USP. Nesta iniciativa, os autores que também coordenaram as atividades relatam como 0 sincronismo entre 0 desenvolvimento dos trabalhos de projeto e construção da Casa Suindara (instalada em um assentamento rural próximo a São Carlos/SP) e os processos de aprendizagem formal permitem uma apreensão qualificada do conhecimento, produzido no próprio canteiro de obras e partilhado com a família moradora - que acaba assumindo protagonismo ativo, como agente de formação no processo de ensino-aprendizagem.

Júlia Theodoro, Raul Maravalhas, Liza Andrade e Caio Silva nos apresentam, na sequência, uma instigante discussão sobre as limitações à inovação, paradoxalmente promovidas pelas próprias políticas de financiamento à provisão habitacional no meio rural - como o PNHR/MCMV. Se, por um lado, o discurso oficial preconiza a utilização de materiais e técnicas mais 'sustentáveis' na produção de nossos habitats, por outro lado, as instâncias também oficiais que fazem a gestão dos programas e recursos para produção desses habitats são os primeiros a evocar a responsabilidade técnica como adversativo na 
implementação de inovações técnicas no âmbito da produção habitacional, embrulhando expectativas de uso de materiais e técnicas alternativas em um sem número de impeditivos burocráticos, implicados nos processos de aprovação de empreendimentos em assentamentos rurais.

Em seguida, temos a contribuição de Maria Cândida de Cerqueira. A autora discute os processos de trabalho de planejamento físicoterritorial em assentamentos rurais que acabam colocando, frente a frente, saberes vernaculares, populares, e o conhecimento técnico formal. Envolvendo distintos agentes, mobilizados em torno de pressupostos por vezes conflituosos, a autora procura compreender as raízes dos conflitos vividos durante certo período num projeto de assentamento - principalmente entre arquitetos e assentados -, o que nos permite especular quanto às eventuais saídas para os antagonismos mais renitentes.

Fechando este Eixo Temático - e esta edição da Paranoá - segue texto assinado por Sarah Andrade, Amadja Borges, Cecília Medeiros e Maria Cândida Cerqueira - por sinal, integrantes do grupo responsável pela realização da primeira edição dos Colóquios "Habitat e Cidadania" (lá em setembro de 2006, em Natal) - o GERAH - Grupo de Estudos em Reforma Agrária e Habitat. $O$ trabalho traz o relato da experiência de construção de uma praça num assentamento no Rio Grande do Norte, em parceria com os assentados e com o Movimentos dos Trabalhadores Rurais Sem Terra - o MST. Essa experiência de produção coletiva de uma praça ensejou a incontornável discussão sobre como são tratados os espaços públicos em assentamentos rurais e qual o seu papel na dimensão formativa do grupo de famílias assentadas: se considerada a dispersão que a vida no campo muitas vezes implica, espaços de sociabilidade como esses passam a assumir vital importância.

Assim, são esses aspectos da vida fora das cidades que elucidam a possibilidade de formas de cidadania distintas daquela que se defende para o cidadão do meio urbano: se consideramos que os direitos reivindicados à 'urbanidade' não podem nem devem ser pensados de forma restrita ao contexto urbano, então devem ser pensados e defendidos de forma extensiva, de modo a alcançar a existência no campo, nas florestas e nas águas. Que o 'habitar da não-cidade' se estabeleça como plano de pensamento e planejamento tanto em Arquitetura e Urbanismo como em políticas públicas, articuladas a partir da realidade que lhe é característica - porém de forma coextensiva à realidade urbana $e$ situadas a partir do pressuposto de uma possível "cidadania sem cidade" (Lopes, 2002).

Como diz José Eli da Veiga, "nem tudo é urbano" (Veiga, 2004).

São Carlos/SP , Florianópolis/SC, Natal/RN

Fevereiro 2017 


\section{Referências}

CARLOS, Ana Fani Alessandri. "Seria o Brasil 'menos urbano do que se calcula?'." Revista Geousp 13, 2003.

GRAZIANO DA SILVA, José. A nova dinâmica da agricultura brasileira. Campinas: UNICAMP, 1998.

LENZI, Cecília Corrêa. A habitação camponesa no programa MCMV. Dissertação (Mestrado em Arquitetura e Urbanismo) - Instituto de Arquitetura e Urbanismo, Universidade de São Paulo, São Carlos, 2017.

LOPES, João Marcos de Almeida. "O Dorso da Cidade: os Sem Terra e a concepção de uma outra Cidade". In: Boaventura de Sousa Santos. (Org.). Produzir para Viver: os Caminhos da Produção não Capitalista. 1a.ed.Rio de Janeiro: Editora Civilização Brasileira, 2002, v. único, p. 283-326.

OLIVEIRA, Ariovaldo Umbelino de. "Geografia Agrária: perspectivas no início do Século XXI." In: O Campo no Século XXI, por Ariovaldo Umbelino de OLIVEIRA, 29-70. São Paulo, SP: Paz e Terra/Casa Amarela, 2004.

VALADARES, Alexandre Arbex. O gigante invisível: território e população rural para além das convenções oficiais. Brasília: IPEA, 2014.

VEIGA, José Eli da. Cidades imaginárias: o Brasil é menos urbano do que se calcula. Campinas, SP: Autores Associados, 2001. 